\title{
Calibration of glacier volume-area relations from surface extent fluctuations and application to future glacier change
}

\author{
Marco MÖLLER, Christoph SCHNEIDER
}

\author{
Department of Geography, RWTH Aachen University, Templergraben 55, D-52056 Aachen, Germany \\ E-mail: marco.moeller@geo.rwth-aachen.de
}

\begin{abstract}
The volume- and area-change evolution of glaciers can be obtained by employing the volume-area scaling approach during mass-balance modelling. This method usually requires information on the initial surface area and ice volume to adjust the volume-area relation to the specific ice body. However, absolute volumetric data on glaciers are very rare, so the applicability of volume-area scaling is limited. In order to use volume-area scaling on glaciers for which only limited information is available, a new method is presented to calibrate the volume-area relation without prior knowledge of this relation by using glacier extent information from different times. To validate the method and illustrate its practicability, we model the range of probable future changes in ice volume and surface area of 'Glaciar Noroeste', an outlet glacier of Gran Campo Nevado ice cap, southern Chilean Patagonia, during the 21st century, based on IPCC SRES scenarios B1 and A2.
\end{abstract}

\section{INTRODUCTION}

The evolution of glacier volume and area can be estimated by employing the volume-area scaling approach (Bahr and others, 1997) during surface mass-balance modelling (e.g. Van de Wal and Wild, 2001; Radić and Hock, 2007). If the studied glacier or ice cap is not in steady state, this method requires information on the initial surface area and ice volume to adjust the volume-area relation to the specific ice body (e.g. Radić and Hock, 2007). However, as absolute volumetric data on glaciers and ice caps are very rare, the applicability of volume-area scaling is limited. Data regarding glacier area are available much more readily.

We present a new method to calibrate the volume-area relation applied in volume- and area-change modelling on the basis of areal data only and no absolute volumetric data. This makes it possible to extend the use of volume-area scaling to less intensively studied glaciers.

To calibrate the volume-area relation, it is necessary to know the surface areas at different dates in combination with the surface topography at the first date. A surface massbalance model extended to incorporate changing glacier area by using the volume-area scaling approach is repeatedly run over the calibration period. The volumearea relation implemented in the model is then changed until the calculated surface area evolution reaches the best possible approximation of observed glacier changes.

The method is applied to an outlet glacier of Gran Campo Nevado (GCN) ice cap in southernmost Chilean Patagonia, unofficially named Glaciar Noroeste (Fig. 1; Schneider and others, 2007b). Its volume-area relation was calibrated using known glacier surface extents from 1984, 1986, 1998, 2002 and 2007. The derived volume-area relation was used to estimate future volume and area changes of Glaciar Noroeste by employing statistically downscaled general circulation model (GCM) data.

Recent mass-balance and glacier change throughout Patagonia has been studied intensively during the past decade (e.g. Casassa and others, 2002; Rivera and others, 2002; Rignot and others, 2003; Stuefer and others, 2007). Most of the studies focused on the Northern and Southern Patagonia Icefields. There are few studies of smaller glaciers of Patagonia and Tierra del Fuego. The regional focus is placed on Cordillera Darwin (e.g. Porter and Santana, 2003), the Cordillera Fueguina Oriental on Tierra del Fuego (e.g. Strelin and Iturraspe, 2007) and GCN ice cap in southernmost Patagonia (e.g. Möller and others, 2007; Schneider and others, 2007a,b; Möller and Schneider, 2008), which forms the largest Patagonian ice mass outside the Northern and Southern Patagonia Icefields $\left(190.5 \mathrm{~km}^{2}\right.$ in 2007). However, to our knowledge, there is no reliable estimation of possible future changes in surface area or ice volume for Patagonian ice caps and glaciers. Hence, we aim not only at introducing a new methodology for glacier volume assessment, but also at presenting a contribution to the assessment of glacier change during the 21 st century in Patagonia.

\section{DATA}

The glacier outlines of Glaciar Noroeste used in this study (Fig. 1) were digitized from aerial photographs taken in 1942, 1984 and 1998, from Landsat Thematic Mapper images taken in 1986 and 2002 and from an Advanced Spaceborne Thermal Emission and Reflection Radiometer (ASTER) image acquired in 2007. Drainage basin boundaries correspond to glacier inventory data presented by Schneider and others (2007b). The surface area of Glaciar Noroeste shows a continuous decline (Table 1).

The glacier surface topography of Glaciar Noroeste is represented by a digital elevation model (DEM) based on topographic maps produced from 1984 airborne photographs (Schneider and others, 2007b). Local reference data needed for statistical downscaling and set-up of the surface mass-balance model, which is based on the degree-day method, were provided by air-temperature and precipitation measurements from an automatic weather station (AWS) operated at Puerto Bahamondes about $7.5 \mathrm{~km}$ to the east of Glaciar Noroeste and $3.5 \mathrm{~km}$ from the eastern ice margin of GCN ice cap at $28 \mathrm{ma.s.l}$. (Schneider and others, 2003). Daily measurements of the AWS cover the period September 2000-August 2005.

The 1984-2099 monthly climate-data time series (Fig. 2) used as input for the modelling procedure were created from 


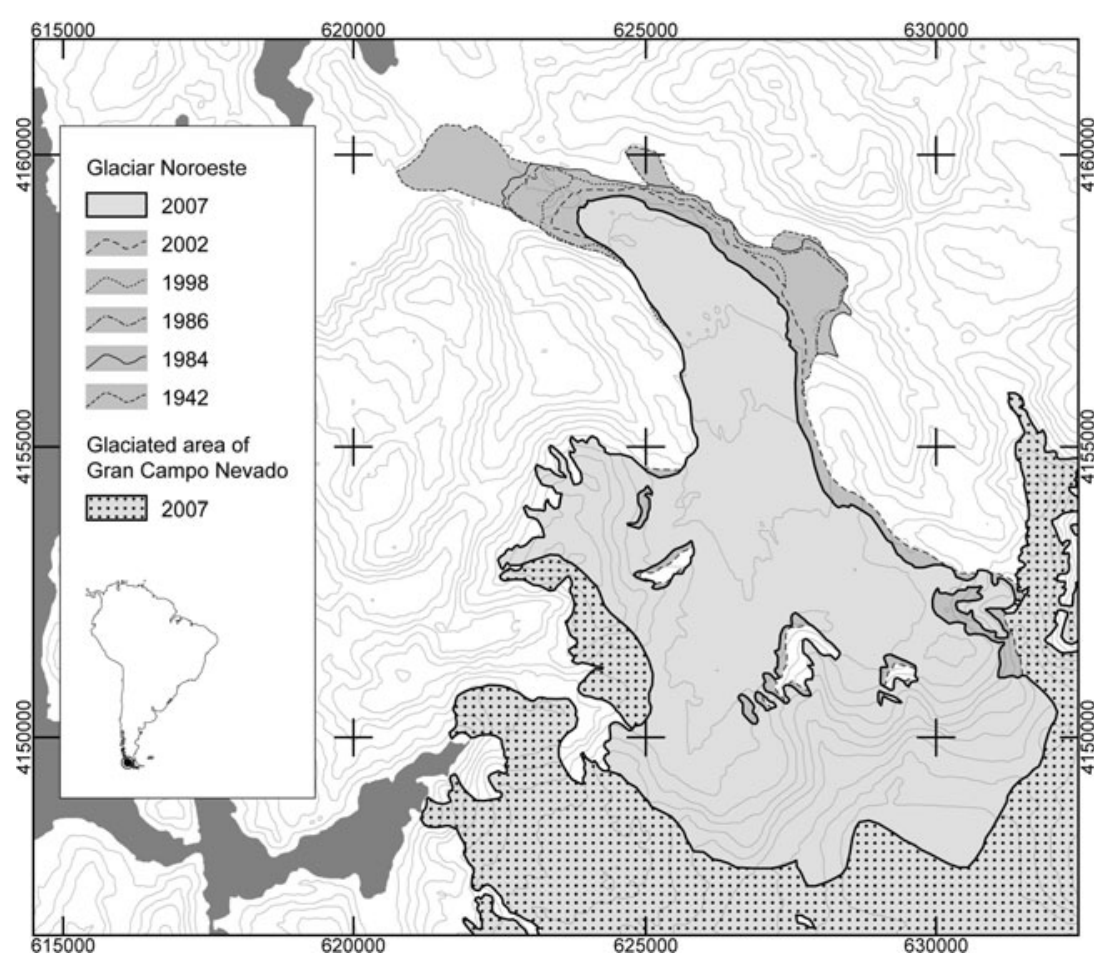

Fig. 1. Location of Glaciar Noroeste and overview of its different glacier extents. Coordinates correspond to Universal Transverse Mercator (UTM) zone 18S. The contour interval is $100 \mathrm{~m}$. Dark grey shading represents the sea.

gridded surface air-temperature and precipitation data. For the period 1984-2006 we used monthly US National Centers for Environmental Prediction (NCEP)/US National Center for Atmospheric Research (NCAR) reanalysis data (resolution $2.5^{\circ} \times 2.5^{\circ}$; Kalnay and others, 1996) provided by the Climate Diagnostics Center, National Oceanic and Atmospheric Administration Cooperative Institute for Research in Environmental Sciences (NOAA-CIRES), Boulder, Colorado, USA (http://www.cdc.noaa.gov/). These data served as the basis for calibration of the volume-area relation (Equation (7)). Output from the third UK Meteorological Office Hadley Centre coupled ocean-atmosphere GCM (HadCM3) was used for the remaining period (200799) of the climate-data time series. The HadCM3 datasets (resolution $3.75^{\circ} \times 2.5^{\circ}$; J.A. Lowe, http://cera-www.dkrz.de/ WDCC/ui/Compact.jsp?acronym =UKMO_HadCM3_ SRESA2_1; J.A. Lowe, http://cera-www.dkrz.de/WDCC/ui/ Compact.jsp?acronym=UKMO_HadCM3_SRESB1_1) represent SRES (Special Report on Emissions Scenarios) scenarios A2 and B1 of the Intergovernmental Panel on Climate Change (IPCC) Fourth Assessment Report (Solomon and

Table 1. Observed and modelled surface extents of Glaciar Noroeste

\begin{tabular}{lcc}
\hline Date & $\begin{array}{c}\text { Observed extent } \\
\mathrm{km}^{2}\end{array}$ & $\begin{array}{c}\text { Modelled extent } \\
\mathrm{km}^{2}\end{array}$ \\
\hline 1942 & 56.4 & $\mathrm{n} . \mathrm{a}$. \\
1984 (30 March) & 54.3 & $\mathrm{n} . \mathrm{a}$. \\
1986 (6 October) & 53.4 & 53.7 \\
1998 (21 February) & 51.0 & 51.2 \\
2002 (16 March) & 50.3 & 50.5 \\
2007 (7 March) & 49.7 & 49.4 \\
\hline
\end{tabular}

others, 2007). Data were provided by the Hadley Centre. All gridded climate data were reduced to subsets of four gridpoints located near GCN ice cap. Data were statistically downscaled according to a combined method (Möller and Schneider, 2008) employing 'local scaling' (Widmann and others, 2003; Salathé, 2005) for adjustment of the annual cycles to local conditions at GCN ice cap and multiple linear regression analysis for creating best-fit combinations of the four gridpoints. NCEP/NCAR reanalysis and HadCM3 A2 time series are the same as in Möller and Schneider (2008), while the HadCM3 B1 time series were created accordingly. The similarity between the downscaled scenarios A2 and B1 is a result of the shift of the different initial airtemperature levels of both scenarios to local conditions at GCN ice cap during the downscaling procedure. As the long-term trends of both scenarios show only small differences, this leads to comparable future time series. A quality assessment of the downscaling procedure based on data from AWS Puerto Bahamondes is presented in Table 2. Results indicate a good performance of the downscaling procedure, with the explained variances of all surface airtemperature time series amounting to at least $84 \%$. Even the synthetic HadCM3 precipitation time series account for explained variances of up to $33 \%$ after the downscaling. Hence, all climate data used are considered an appropriate basis for future glacier evolution modelling.

\section{METHODS}

\section{Surface mass-balance model}

The modelling of glacier volume and area changes builds upon an altered version of the surface mass-balance model described by Möller and others (2007). Within the model, ablation is calculated using the degree-day method (e.g. Braithwaite, 1981; Ohmura, 2001; Hock, 2003) and 

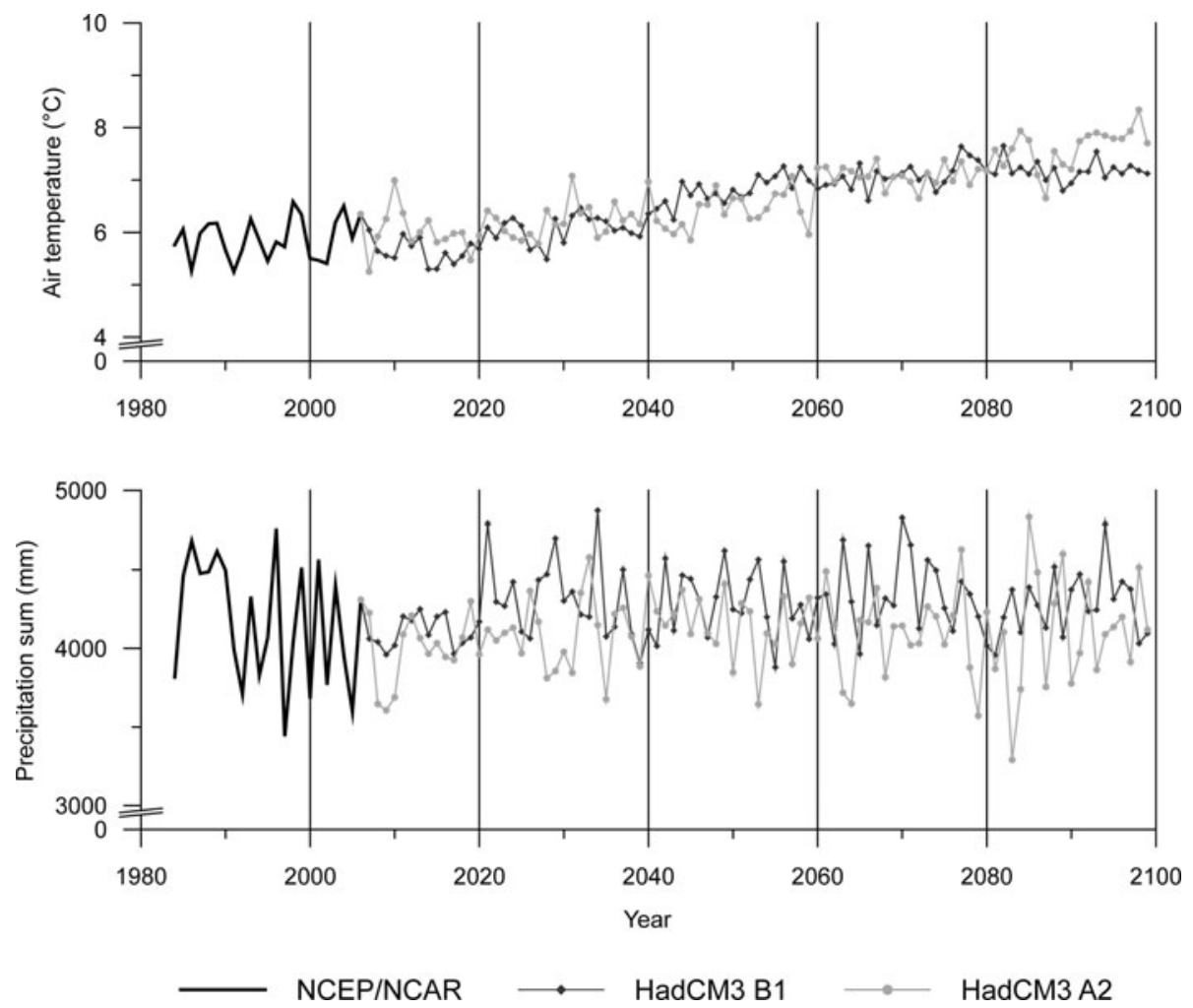

Fig. 2. Downscaled air-temperature and precipitation time series for 1984-2099. The period 1984-2006 is covered by NCEP/NCAR reanalysis data, the period 2007-99 by different HadCM3 data.

accumulation results directly from altitude-dependent sums of solid precipitation. The computation of ablation, a, at a specific altitude, $z$, is based on the positive degree-day sum, $\mathrm{DD}^{+}$of the considered month, $i$, and an empirically derived degree-day factor, $f$. It is calculated as

$$
a_{z, i}=f D_{z, i}^{+} \text {. }
$$

Following Braithwaite (1984) and Marshall (2006), the calculation of $\mathrm{DD}_{z, i}^{+}$is based upon the integral over the positive interval of the probability density function of air temperature $\left(\mathrm{PDF}_{T}\right)$ of the respective month, $p_{i}\left(T_{z}\right)$; (Fig. 3; Equation (4)):

$$
\mathrm{DD}_{z, i}^{+}=D_{i} \overline{T_{z, i}^{+}} \int_{0}^{\infty}\left[p_{i}\left(T_{z}\right)\right] \mathrm{d} T_{z}
$$

Table 2. Performance of the combined downscaling procedure of air-temperature and precipitation data. Measurements at the AWS during September 2001-August 2005 serve for comparison. Significance levels according to Student's $t$ test refer to linear correlations between downscaled and measured data

\begin{tabular}{lcc}
\hline Dataset & $R^{2}$ & $\begin{array}{c}\text { Significance level incl. } \\
\text { autocorrelation } \\
\%\end{array}$ \\
& & $\%$ \\
\hline NCEP/NCAR air temperature & 0.94 & 99.9 \\
NCEP/NCAR precipitation & 0.52 & 99.9 \\
HadCM3 (A2) air temperature & 0.84 & 99.9 \\
HadCM3 (A2) precipitation & 0.19 & 99.5 \\
HadCM3 (B1) air temperature & 0.87 & 99.9 \\
HadCM3 (B1) precipitation & 0.33 & 99.9 \\
\end{tabular}

$D_{i}$ is the number of days of the respective month. $\overline{T_{z, i}^{+}}$is the mean of all positive monthly air temperatures. It is calculated by solving

$$
\int_{0}^{\overline{T_{z, i}^{+}}}\left[p_{i}\left(T_{z}\right)\right] \mathrm{d} T_{z}-\int_{\overline{T_{z, i}^{+}}}^{\infty}\left[p_{i}\left(T_{z}\right)\right] \mathrm{d} T_{z}=0
$$

for $\overline{T_{z, i}^{+}}$(Fig. 3). The employed $\mathrm{PDF}_{T}$ is the normal

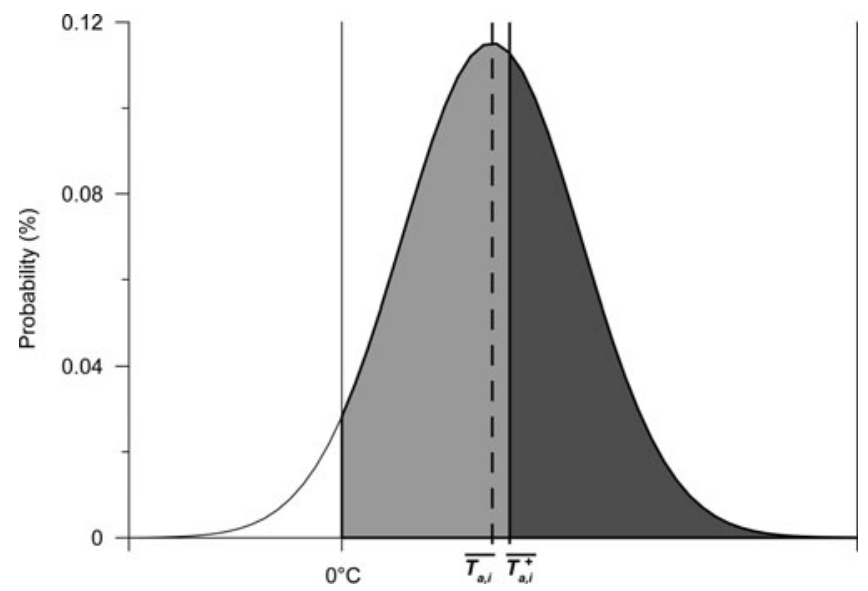

Fig. 3. $\mathrm{PDF}_{T}$ for $\mathrm{GCN}$ ice cap for any given mean monthly air temperature, $\overline{T_{\mathrm{a}, i}}$. Grey areas mark the cumulated probability of positive air temperature. $\overline{T_{\mathrm{a}, i}^{+}}$subdivides the cumulated probability of positive air temperature into parts of equal size indicated by light grey and dark grey areas. Standard deviations of the $\mathrm{PDF}_{T}$ are based on measurements carried out at AWS Puerto Bahamondes between September 2000 and August 2005. 
distribution

$$
p_{i}\left(T_{z}\right)=\frac{1}{\sigma \sqrt{2 \pi}} \exp \left[-\frac{1}{2}\left(\frac{T_{z}-\overline{T_{z, i}}}{\sigma}\right)^{2}\right]
$$

with $\sigma$ representing the standard deviation of air temperature and $\overline{T_{z, i}}$ the mean monthly air temperature.

The accumulation, $c$, at a specific altitude, $z$, during a specific month, $i$, likewise depends on the $\mathrm{PDF}_{T}$ (Equation (4)). It is calculated as the proportion of solid precipitation of the monthly precipitation sum $\left(P_{z, i}\right)$ according to Marshall (2006) as

$$
c_{z, i}=P_{z, i} \int_{-\infty}^{0}\left[p_{i}\left(T_{z}\right)\right] \mathrm{d} T_{z}
$$

It thus features the probability of negative air temperatures as scaling factor, so that solid precipitation is limited to air temperatures below $0^{\circ} \mathrm{C}$.

To obtain the specific mass balance at each altitude, ablation is subtracted from accumulation. To convert the specific mass balance into volume changes, the model is extended to a surface mass-balance model according to Braithwaite and Zhang (2000) on the basis of the DEM representing the glacier surface, $A$. Volume changes, $\Delta V$, are calculated by integrating the specific mass balance over all altitudes:

$$
\Delta V_{i}=\frac{1}{\rho_{\text {Ice }}} \int_{A}\left(c_{z, i}-a_{z, i}\right) d z
$$

with $\rho_{\text {Ice, }}$ the density of glacier ice, set to 0.9 (Paterson, 1994; Möller and others, 2007). At this stage (Equations (16)) the surface mass-balance model architecture lacks any dynamic adjustment of the glacier surface area to volume changes.

\section{Volume-area scaling}

According to Bahr and others (1997), the volume, $V$, of any glacier or ice cap is related to its surface area, $A$, by a simple power-law equation based on a dimensionless scaling exponent, $\gamma$, that depends on glacier type:

$$
V=A^{\gamma} \text {. }
$$

It is extended by a scaling coefficient, sc, to account for any glacier, either in steady state or not (Van de Wal and Wild, 2001; Radić and Hock, 2007):

$$
V=\operatorname{sc} A^{\gamma} \text {. }
$$

In steady state, $\mathrm{sc}=1$. Otherwise, $\mathrm{sc}$ has to be obtained for each glacier individually. This can be done either by calculating it from the glacier's known initial surface area and ice volume (Radić and Hock, 2007) or by applying the method presented here.

\section{Area- and volume-change modelling}

Based on the volume-area relation, and according to a method outlined in Van de Wal and Wild (2001) and Radić and Hock (2007), the surface mass-balance model is augmented by an area- and volume-change model. It employs the volume-area scaling equation (Equation (7)) for continuous adjustment of glacier surface area to computed volume changes. During model runs, the monthly changes of glacier volume calculated by the area- and volume-change model, $\Delta V$, are summed at the end of each year, $y$. This sum is then added to the existing glacier volume, $V$, in order to calculate a new glacier area, $A$, for the following year according to

$$
A_{y+1}=\left(\frac{V_{y}+\Delta V_{y}}{\mathrm{sc}}\right)^{\frac{1}{\gamma}} \text {. }
$$

For areas smaller than the initial glacier area, the lower ice margins are moved upwards until the remaining surface extent equals the previously calculated new glacier area. This method is similar to an approach used by Paul and others (2007) who carried out glacier area modelling depending on varying accumulation-area ratios. During model runs, the glacier area is reduced by cutting off pixels of the DEM in order of increasing altitude. Calculation of $\Delta V$ for the particular year is then based on the reduced DEM. In case of positive mass balance, the enlargement of the glacier area is performed by extending it to formerly icecovered regions (Fig. 1). During model runs, this expansion of glacier area is done by adding pixels to the DEM in order of decreasing altitude.

\section{Modelling of future glacier change}

In order to illustrate the applicability of the method outlined above, we used it to derive the range, i.e. the upper and lower limits, of probable area and volume changes of Glaciar Noroeste in the 21 st century. Therefore, the areaand volume-change modelling procedure was initialized in 1984 featuring the volume-area relation obtained from the calibration procedure (Equation (9)). The model was driven by statistically downscaled NCEP/NCAR reanalysis data and HadCM3 GCM data representing the IPCC SRES scenarios B1 and A2 (Fig. 2).

\section{MODEL CALIBRATION}

We introduce a new method to calibrate the volume-area relation (Equation (7)) of a specific glacier that is not in steady state. The basic idea is to run the area- and volume-change model from a known initial state over a certain period featuring one or, ideally, more known surface extents of the respective ice body. Referring to Bahr and others (1997), we assume (see below) a fixed value for the scaling exponent, $\gamma$ (Equation (7)), and during calibration runs we alter the factor sc iteratively to seek the best fit between modelled glacier area change and observed glacier-extent records by minimizing the root-mean-square (RMS) difference.

For the volume-area scaling equation (Equation (7)), Bahr and others (1997) obtained a dimensionless scaling exponent of $\gamma=1.375$ for valley glaciers. They also outline that other studies resulted in slightly different scaling exponents, which is in good agreement with findings by Paterson (1972), Chen and Ohmura (1990) and Radić and others (2007). Considerations by Van de Wal and Wild (2001) suggest an error range for $\gamma$ of \pm 0.125 . Accordingly, in this study, $\gamma$ for Glaciar Noroeste is assumed to be $1.375 \pm 0.125$, which combines the scaling exponent given by Bahr and others (1997) and the error range of Van de Wal and Wild (2001).

The 1984 glacier surface extent (Fig. 1) and topography were used as initial conditions for the area- and volumechange model runs. The remaining boundary and starting conditions of the model were chosen according to Möller and others (2007) and Schneider and others (2007a). The degree-day factors (Equation (1)) of the surface mass-balance model were set to $f=7.0 \mathrm{~mm}$ w.e. $\mathrm{K}^{-1} \mathrm{~d}^{-1}$ for ice surface and $f=3.5 \mathrm{~mm}$ w.e. $\mathrm{K}^{-1} \mathrm{~d}^{-1}$ for snow surface. An initial 
snow-cover pattern ranging between $0 \mathrm{~mm}$ w.e. thickness below $300 \mathrm{~m}$ a.s.l. and $500 \mathrm{~mm}$ w.e. thickness above $700 \mathrm{~m}$ a.s.l. was included. A further increase of snow depth above this altitude has no influence on model results. Therefore, it is kept constant in favour of model simplicity. Air-temperature and precipitation lapse rates were set to $0.63 \mathrm{~K}(100 \mathrm{~m})^{-1}$ and $5 \%(100 \mathrm{~m})^{-1}$ respectively, as estimated from different AWS measurements documented by Schneider and others (2003). The standard deviation of mean daily air temperature at GCN ice cap $\left(\sigma=3.5^{\circ} \mathrm{C}\right)$ required for set-up of the $\operatorname{PDF}_{T}$ (Equation (4)) is calculated from the mean daily temperatures of the AWS (September 2000-August 2005).

The known glacier surface extents of 1986, 1998, 2002 and 2007 serve as benchmarks for the best-fit calibration procedure. Model runs are driven by downscaled NCEP/ NCAR reanalysis data of the period 1984-2006 (Fig. 2).

Results yield $\mathrm{sc}=0.311 \mathrm{~m}^{3-2 \gamma}$, and Equation (7) thus becomes

$$
V=0.311 A^{1.375}
$$

for Glaciar Noroeste. Table 1 presents the modelled and observed glacier extents, providing an overview of the model performance, and showing that modelled glacier changes provide a reasonable estimate of the surface extents observed within the calibration period. The RMS error between observed and modelled values amounts to just $0.24 \mathrm{~km}^{2}$, indicating a good overall reliability of the areaand volume-change model.

\section{ERROR ASSESSMENT}

For assessment of the error range of both area- and volumechange modelling, three different sources of errors have to be considered. The set is formed by (1) the RMS difference of the best-fit calibration procedure; (2) an additional error range resulting from the \pm 0.125 uncertainty of the scaling exponent of the volume-area relation itself; and (3) possible inaccuracies of the degree-day model calibration.

The RMS error of the best-fit calibration procedure was calculated using observed and modelled extents of Glaciar Noroeste in 1986, 1998, 2002 and 2007 (Table 1). It amounts to $\pm 0.24 \mathrm{~km}^{2}$ for area-change modelling, $E_{A, 1}$, and is assumed to be constant in time. The associated error range in volume-change modelling, $E_{V, 1}$, is thus calculated to be $\pm 0.04 \mathrm{~km}^{3}$ according to the volume-area relation (Equation (9)).

For assessment of the error resulting from the \pm 0.125 uncertainty of the scaling exponent of the volume-area relation (Equation (9)), the area and volume changes of Glaciar Noroeste during the 21st century were computed repeatedly using not only Equation (9) for the area- and volume-change model but also Equation (7) calibrated for $\gamma=1.25$ and $\gamma=1.5$. The differences between the resulting three modelled area-change time series show clearly progressive characteristics. Maximum differences are reached in 2099 and amount to $\pm 0.22 \mathrm{~km}^{2}$ (B1) and $\pm 0.24 \mathrm{~km}^{2}$ (A2). The deviations of volume-change modelling prove to vary only slightly with time. Starting with a value of $\pm 1.21 \mathrm{~km}^{3}$ in 1984 , they show an increase to slightly higher maximum values during the first three decades of the 21 st century. Afterwards, deviations drop continuously until 2099. Minimum values are reached at $\pm 1.19 \mathrm{~km}^{3}$ (B1) and $\pm 1.18 \mathrm{~km}^{3}$ (A2) respectively. The corresponding error ranges result from the maximal deviations of each year, $E(y)_{A, 2}$ and $E(y)_{V, 2}$.

The impacts of calibration inaccuracies of the degree-day model, i.e. of the degree-day factors, were also analysed by performing additional area- and volume-change model runs. For error assessment the degree-day factors, $f_{\text {ice }}=7.0 \mathrm{~mm}$ w.e. $\mathrm{K}^{-1} \mathrm{~d}^{-1}$ and $f_{\text {snow }}=3.5 \mathrm{~mm}$ w.e. $\mathrm{K}^{-1} \mathrm{~d}^{-1}$, were varied by \pm 1.0 and $\pm 0.5 \mathrm{~mm} \mathrm{~K}^{-1} \mathrm{~d}^{-1}$ respectively. Results of areachange modelling yield a continuous but decreasing progression of deviations throughout the modelling period. Maximum values are reached in 2099 and amount to $\pm 3.1 \mathrm{~km}^{2}$ (B1) and $\pm 3.2 \mathrm{~km}^{2}$ (A2). The uncertainty in the modelled volume-change time series shows similar characteristics, with deviations of up to $\pm 0.9 \mathrm{~km}^{3}$ (B1 and A2). Maximum deviations of each respective year are taken as error ranges $E(y)_{A, 3}$ and $E(y)_{V, 3}$.

The total error ranges of the area- (Equation (10a)) and volume-change (Equation (10b)) time series can be described by

$$
E(y)_{A, \text { all }}=\sqrt{E_{A, 1}{ }^{2}+E(y)_{A, 2}{ }^{2}+E(y)_{A, 3}{ }^{2}}
$$

and

$$
E(y)_{V, \text { all }}=\sqrt{E_{V, 1}^{2}+E(y)_{V, 2}^{2}+E(y)_{V, 3}^{2}} .
$$

The total error ranges of the area-change time series show a continuous increase with time. They reach maximum uncertainties of $\pm 3.2 \mathrm{~km}^{2}$ (B1 and A2) in 2099 (Fig. 4). This corresponds to values of not more than $\pm 9 \%$ for any specific year. Regarding the error ranges of the volume-change time series, only a slight increase with time is evident. Uncertainties increase continuously from $\pm 1.2 \mathrm{~km}^{3}$ in 1984 to $\pm 1.5 \mathrm{~km}^{3}$ (B1 and A2) in 2099 (Fig. 5). Thus, they increase from consistent values of $\pm 9 \%$ in 1984 to $20 \%$ (B1) and $21 \%$ (A2) in 2099.

The accuracy of modelled area changes proved to be highly reliable. This is documented by an RMS error of just $0.24 \mathrm{~km}^{2}$. Moreover, the maximum deviation between modelled and observed glacier areas throughout the calibration period (i.e. the years 1986, 1998, 2002 and 2007) amounts to no more than $0.3 \mathrm{~km}^{2}$, i.e. $<0.5 \%$.

\section{RESULTS AND DISCUSSION Volume-area relation}

The calibrated volume-area relation of Glaciar Noroeste (Equation (9)) assigns an overall ice volume of $13.4 \mathrm{~km}^{3}$ to the 1984 glacier surface extent of $54.3 \mathrm{~km}^{2}$. This implies a reasonable mean ice thickness of $\sim 250 \mathrm{~m}$. The accuracy of this estimation was calculated to be $\pm 1.2 \mathrm{~km}^{3}$.

It can thus be concluded that our method of calibrating the volume-area relation of a specific glacier by the exclusive use of data on surface area change is a successful and accurate means of estimating ice volume. Present glacier volume is calculated with a potential error range of $9-11 \%$ (Fig. 5). However, it must be remembered that the accuracy of future glacier evolution modelling deteriorates for the later years due to the increase in the associated total error range.

\section{Future glacier evolution}

The results of modelling future ice evolution yield values of probable glacier surface area reduction by 2099 ranging from $18.9 \mathrm{~km}^{2}$ (B1) to $19.4 \mathrm{~km}^{2}$ (A2). This results in the 


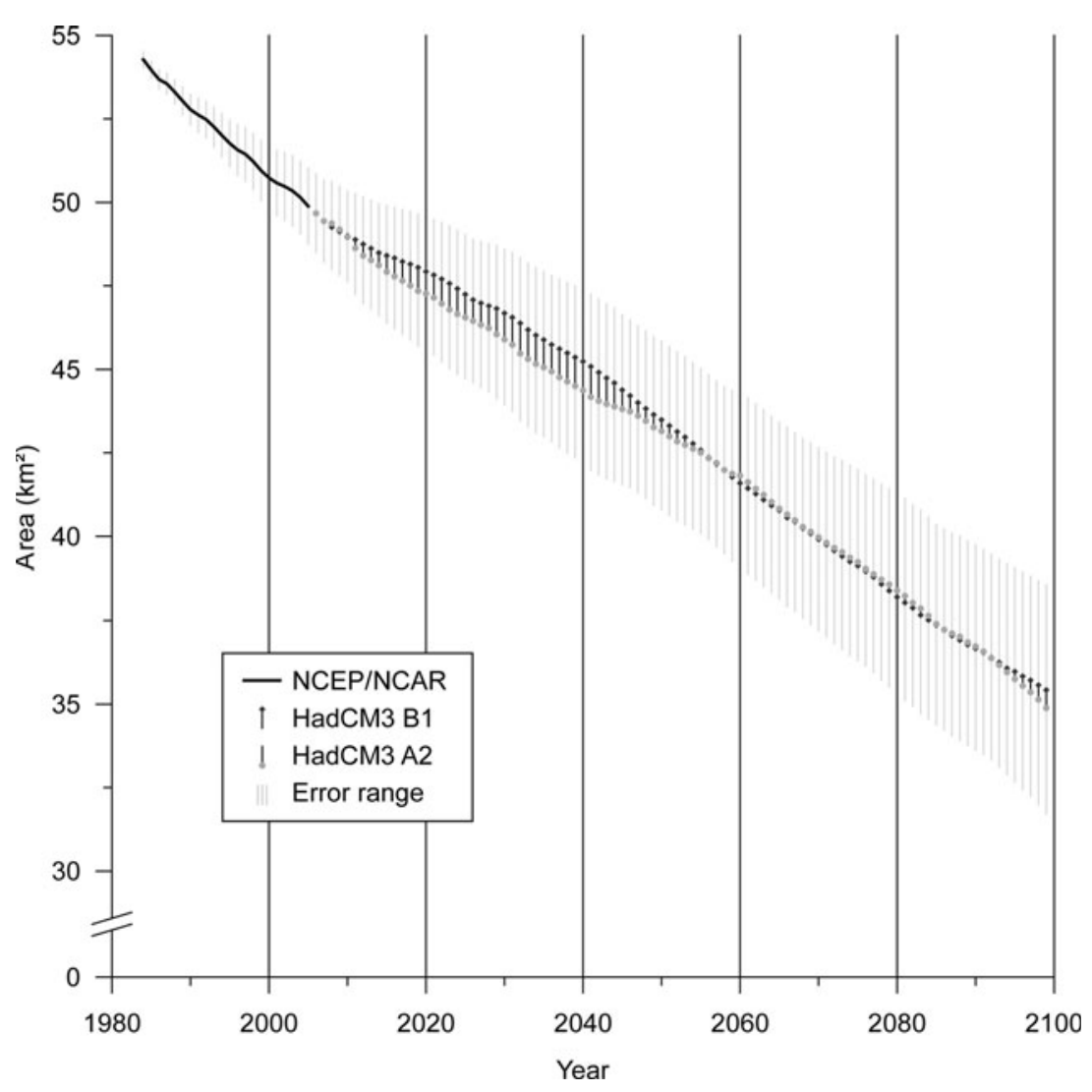

Fig. 4. Evolution of the surface area extent of Glaciar Noroeste for the period 1984-2099.

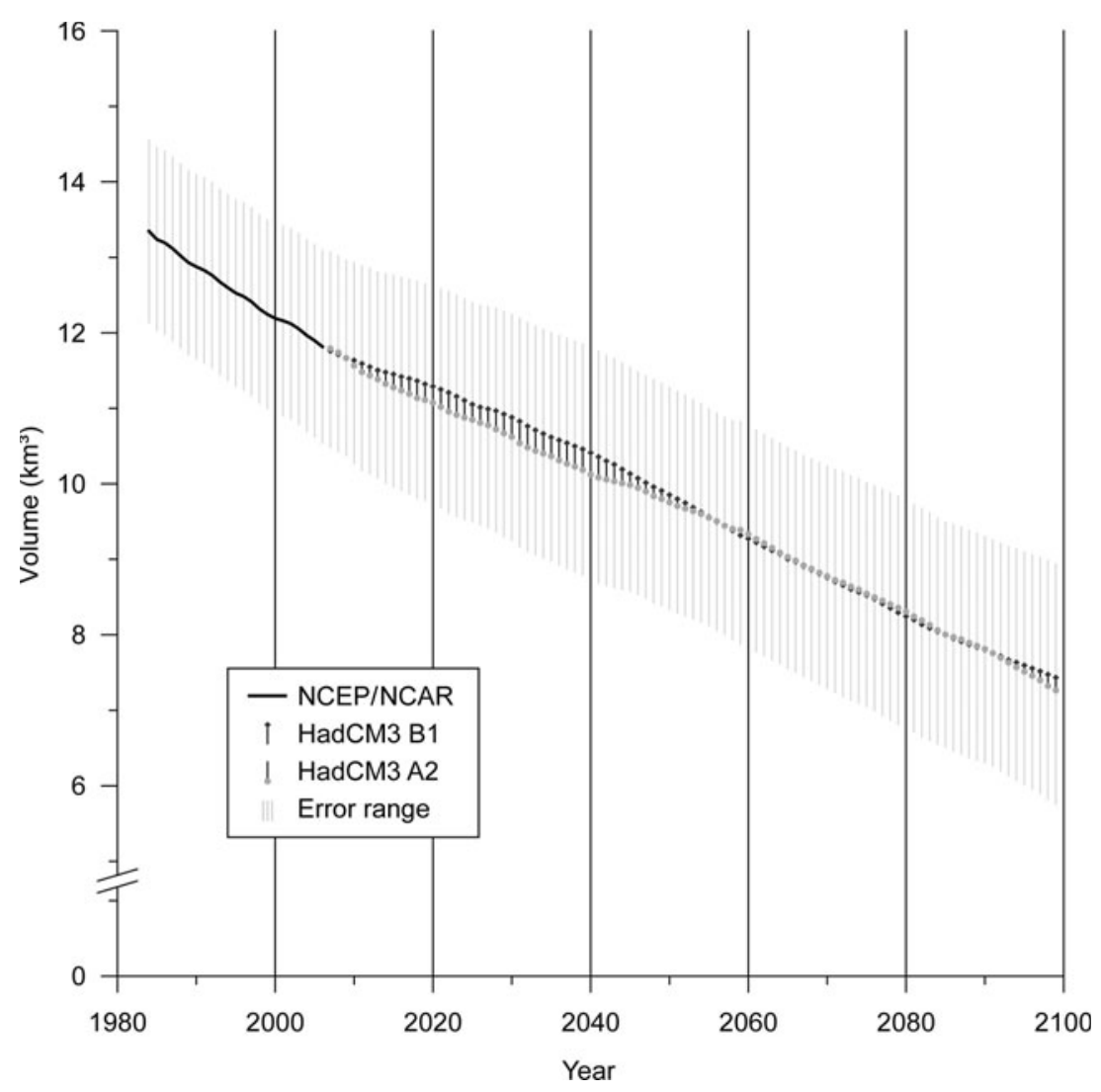

Fig. 5. Volume-change evolution of Glaciar Noroeste for the period 1984-2099. 


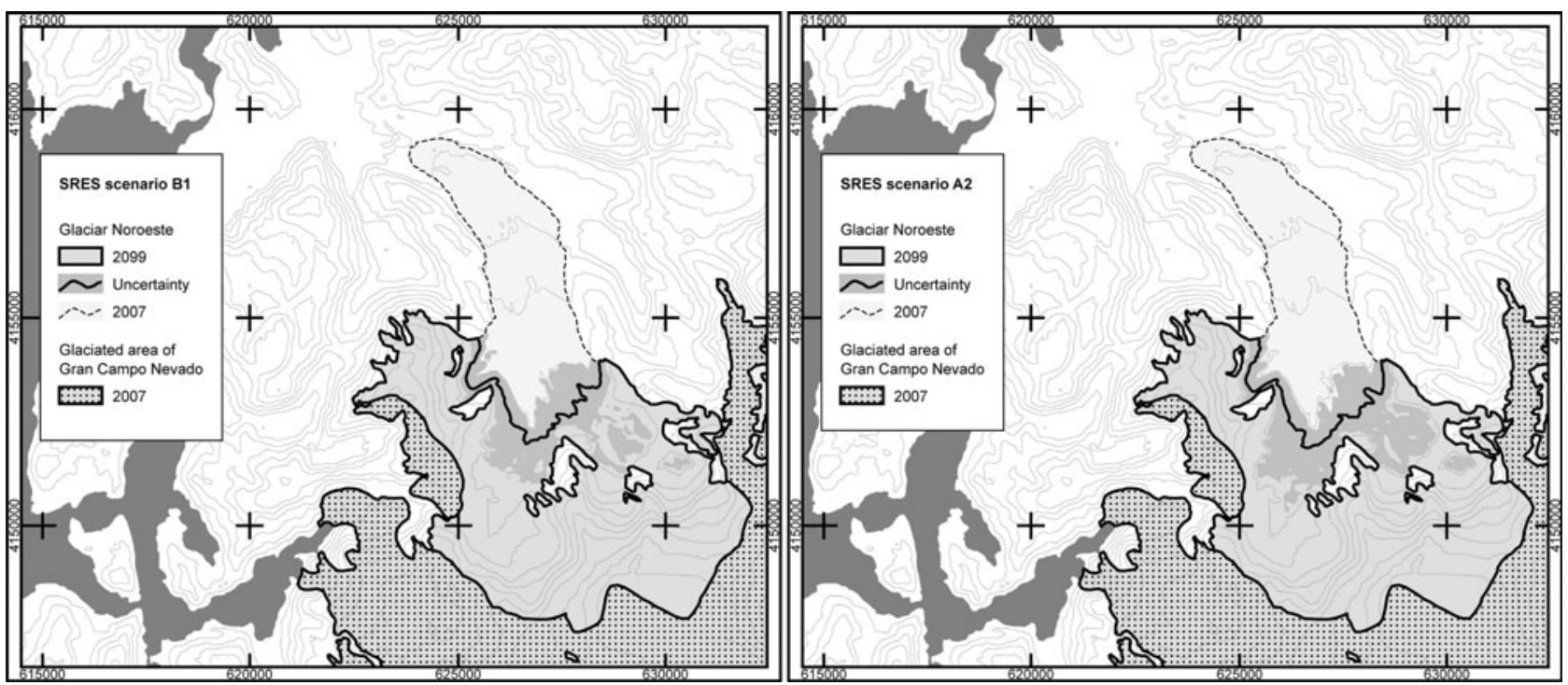

Fig. 6. Estimated extents of Glaciar Noroeste in 2099 resulting from climate forcing according to IPCC SRES scenarios B1 (left) and A2 (right). Coordinates correspond to UTM zone 18S. The contour interval is $100 \mathrm{~m}$. Dark grey shading represents the sea. Given uncertainty ranges correspond to the results of Equation (10a).

surface area of Glaciar Noroeste being reduced to $34.9 \pm 3.2 \mathrm{~km}^{2}$ at the end of the $21 \mathrm{st}$ century for A2 (Fig. 4). In scenario B1, Glaciar Noroeste shrinks to $35.4 \pm 3.2 \mathrm{~km}^{2}$ (Fig. 4). This loss in area corresponds to between $35 \%$ (B1) and 36\% (A2) when compared with the initial surface area in 1984. Volumetric results (Fig. 5) reveal a probable ice volume loss ranging from $5.9 \mathrm{~km}^{3}$ (B1) to $6.1 \mathrm{~km}^{3}$ (A2). The calibrated initial ice volume of $13.4 \pm 1.2 \mathrm{~km}^{3}$ is estimated to decrease to $7.4 \pm 1.5 \mathrm{~km}^{3}$ (B1) and $7.3 \pm 1.5 \mathrm{~km}^{3}$ (A2). This implies a loss of ice volume of $>40 \%$ in both cases.

The associated recession of the lower ice margins was estimated to altitudes of $539 \pm 37 \mathrm{~m}$ a.s.l. (B1) and $546 \pm 40 \mathrm{~m}$ a.s.l. (A2). Figure 6 shows the different estimates of surface extent of Glaciar Noroeste in 2099. The modelling procedure does not account for lowering of the glacier surface. The potential elevation feedback (e.g. Raymond and others, 2005) resulting in altered ablation and accumulation amounts is thus neither considered nor quantified. The resulting additional error range of unknown magnitude due to feedback mechanisms should not be ignored when the presented area and volume changes are interpreted. Nevertheless, the small differences between the B1 and A2 time series in either case suggest only a weak dependency of Glaciar Noroeste on the intensity of oncoming climate change.

\section{CONCLUSION}

We have presented a new method to calibrate the volumearea relation of a specific glacier or ice cap without requiring information regarding absolute ice volume. The only data needed for the calibration process are a DEM representing the terrain at the beginning of a calibration period and several known glacier surface extents.

Calibration results combined with error assessment yield a good model performance. Area changes prove to be modelled with high accuracy within the period 1984-2007. Initial ice volume is estimated with a precision of $\pm 10 \%$. However, this finding is not derived from ice volume observations but is merely based on error propagation. Our method has high potential for estimating the volume of glaciers. The area- and volume-change model also proved to be a useful and reliable means of modelling future glacier evolution. Due to its low requirements regarding input data, the method is especially valuable for studies on remote and thus less intensively studied regions.

The area- and volume-change model was calibrated and tested for Glaciar Noroeste, an outlet glacier of GCN ice cap. The range of future volume and area changes of Glaciar Noroeste until 2099 was estimated. Model results yield a decline of the glaciated area of Glaciar Nooroeste from $54.3 \mathrm{~km}^{2}$ in 1984 to between $35.4 \pm 3.2 \mathrm{~km}^{2}$ (B1) and $34.9 \pm 3.2 \mathrm{~km}^{2}$ (A2) at the end of the $21 \mathrm{st}$ century (Fig. 4). This change will probably be accompanied by a recession of the lower ice margins to altitudes between $539 \pm 37 \mathrm{~m}$ a.s.l. (B1) and $546 \pm 40 \mathrm{~m}$ a.s.l. (A2) when assuming a hypsometrically consistent retreat in the lowermost glacier regions (Fig. 6). The associated loss of ice volume (Fig. 5) was estimated to range between $5.9 \mathrm{~km}^{3}$ (B1) and $6.1 \mathrm{~km}^{3}$ (A2). The small difference in probable future glacier changes of Glaciar Noroeste suggests a weak dependency on the intensity of oncoming climate change, which in this region is dominated by a temperature increase of $<2{ }^{\circ} \mathrm{C}$ in both B1 and A2 scenarios by the end of the century, with insignificant change in precipitation (Fig. 2).

\section{ACKNOWLEDGEMENTS}

We thank all participants in the numerous field campaigns realized since 1999 for their efforts in obtaining massbalance and AWS data at GCN ice cap. Data acquisition was partly funded by grant No. Schn-680 1/1 issued by the German Research Society (Deutsche Forschungsgemeinschaft: DFG). The ASTER image used in Figure 1 was kindly provided by Global Land Ice Measurements from Space (GLIMS). Comments by J.G. Cogley on both this and an earlier version of the paper are gratefully acknowledged, as are remarks by G. Casassa and an anonymous reviewer, which helped to improve the manuscript. 


\section{REFERENCES}

Bahr, D.B., M.F. Meier and S.D. Peckham. 1997. The physical basis of glacier volume-area scaling. J. Geophys. Res., 102(B9), 20,355-20,362.

Braithwaite, R.J. 1981. On glacier energy balance, ablation, and air temperature. J. Glaciol., 27(97), 381-391.

Braithwaite, R.J. 1984. Calculation of degree-days for glacierclimate research. Z. Gletscherkd. Glazialgeol., 20, 1-20.

Braithwaite, R.J. and Y. Zhang. 2000. Sensitivity of mass balance of five Swiss glaciers to temperature changes assessed by tuning a degree-day model. J. Glaciol., 46(152), 7-14.

Casassa, G., F.V. Sepúlveda and R.M. Sinclair, eds. 2002. The Patagonian icefields: a unique natural laboratory for environmental and climate change studies. New York, Kluwer Academic Press.

Chen, J. and A. Ohmura. 1990. Estimation of Alpine glacier water resources and their change since the 1870s. IAHS Publ. 193 (Symposium at Lausanne 1990 - Hydrology in Mountainous Regions), 127-135.

Hock, R. 2003. Temperature index melt modelling in mountain areas. J. Hydrol., 282(1-4), 104-115.

Kalnay, E. and 21 others. 1996. The NCEP/NCAR 40-year reanalysis project. Bull. Am. Meteorol. Soc., 77(3), 437-471.

Marshall, S.J. 2006. Modelling glacier response to climate change. In Knight, P.G., ed. Glacier science and environmental change. Oxford, Blackwell Publishing, 163-173.

Möller, M. and C. Schneider. 2008. Climate sensitivity and massbalance evolution of Gran Campo Nevado ice cap, southwest Patagonia. Ann. Glaciol., 48, 32-42.

Möller, M., C. Schneider and R. Kilian. 2007. Glacier change and climate forcing in recent decades at Gran Campo Nevado, southernmost Patagonia. Ann. Glaciol., 46, 136-144.

Ohmura, A. 2001. Physical basis for the temperature-based meltindex method. J. Appl. Meteorol., 40(4), 753-761.

Paterson, W.S.B. 1972. Laurentide ice sheet: estimated volumes during Late Wisconsin. Rev. Geophys. Space Phys., 10(4), 885-917.

Paterson, W.S.B. 1994. The physics of glaciers. Third edition. Oxford, etc., Elsevier.

Paul, F., M. Maisch, C. Rothenbühler, M. Hoelzle and W. Haeberli. 2007. Calculation and visualisation of future glacier extent in the Swiss Alps by means of hypsographic modelling. Global Planet. Change, 55(4), 343-357.

Porter, S.C. and A. Santana. 2003. Rapid 20th century retreat of Ventisquero Marinelli in the Cordillera Darwin Icefield. An. Inst. Patagonia, 31, 17-26.

Radić, V. and R. Hock. 2006. Modeling future glacier mass balance and volume changes using ERA-40 reanalysis and climate models: sensitivity study at Storglaciären, Sweden. J. Geophys. Res., 111(F3), F03003. (10.1029/2005JF000440.)

Radić, V., R. Hock and J. Oerlemans. 2007. Volume-area scaling vs flowline modelling in glacier volume projections. Ann. Glaciol., 46, 234-240.

Raymond, C.F., T.A. Neumann, E. Rignot, K. Echelmeyer, A. Rivera and G. Casassa. 2005. Retreat of Glaciar Tyndall, Patagonia, over the last half-century. J. Glaciol., 51(173), 239-247.

Rignot, E., A. Rivera and G. Casassa. 2003. Contribution of the Patagonian icefields of South America to sea level rise. Science, 302(5644), 434-437.

Rivera, A., C. Acuña, G. Casassa and F. Bown. 2002. Use of remotely-sensed and field data to estimate the contribution of Chilean glaciers to eustatic sea-level rise. Ann. Glaciol., 34, 367-372.

Salathé, E.P. 2005. Downscaling simulations of future global climate with application to hydrologic modelling. Int. J. Climatol., 25(4), 419-436.

Schneider, C., M. Glaser, R. Kilian, A. Santana, N. Butorovic and G. Casassa. 2003. Weather observations across the Southern Andes at $53^{\circ} \mathrm{C}$. Phys. Geogr., 24(2), 97-119.

Schneider, C., R. Kilian and M. Glaser. 2007a. Energy balance in the ablation zone during the summer season at the Gran Campo Nevado Ice Cap in the Southern Andes. Global Planet. Change, 59(1-4), 175-188.

Schneider, C., M. Schnirch, C. Acuña, G. Casassa and R. Kilian. 2007b. Glacier inventory of the Gran Campo Nevado Ice Cap in the Southern Andes and glacier changes observed during recent decades. Global Planet. Change, 59(1-4), 87-100.

Solomon, S. and 7 others, eds. 2007. Climate change 2007: the physical science basis. Contribution of Working Group I to the Fourth Assessment Report of the Intergovernmental Panel on Climate Change. Cambridge, etc., Cambridge University Press.

Strelin, J. and R. Iturraspe. 2007. Recent evolution and mass balance of Cordón Martial glaciers, Cordillera Fueguina Oriental. Global Planet. Change, 59(1-4), 17-26.

Stuefer, M., H. Rott and P. Skvarca. 2007. Glaciar Perito Moreno, Patagonia: climate sensitivities and glacier characteristics preceding the 2003/04 and 2005/06 damming events. J. Glaciol., 53(180), 3-16.

Van de Wal, R.S.W. and M. Wild. 2001. Modelling the response of glaciers to climate change by applying volume-area scaling in combination with a high resolution GCM. Climate Dyn., 18(3-4), 359-366.

Widmann, M., C.S. Bretherton and E.P. Salathé. 2003. Statistical precipitation downscaling over the northwestern United States using numerically simulated precipitation as a predictor. J. Climate, 16(5), 799-816. 